Genserik L. L. Reniers, Int. J. of Safety and Security Eng., Vol. 2, No. 1 (2012) 69-79

\title{
SECURITY OF MULTIMODAL HAZMAT TRANSPORTS: EMPIRICAL FINDINGS AND FUTURE DIRECTIONS
}

\author{
GENSERIK L.L. RENIERS ${ }^{1,2}$ \\ ${ }^{1}$ Antwerp Research Group on Safety and Security (ARGoSS), University of Antwerp, Prinsstraat, Antwerp. \\ ${ }^{2}$ Centre for Economics and Corporate Sustainability (CEDON), HUB, KULeuven, Stormstraat, Brussels.
}

\begin{abstract}
This article investigates and questions in what ways the management methods and mathematical approaches, which are available for taking effective security measures in case of hazmat transportation, can be enhanced and whether they are adequately applied in industrial practice. After all, transportation of dangerous goods is a highly complex problem characterized with multi-modality and with multiple stakeholders and decision makers. Empirical findings, for example, suggest that companies transporting hazardous materials do not consider security to be an essential decision-influencing parameter, for example, as regard the option to choose for multi-modal transportation. This paper explains three possible ways to advance academic research (and to link it with industrial practice) in this ever more important societal domain of interest: multi-criteria modeling, game-theoretical modeling, and the use of meta-heuristics.
\end{abstract}

Keywords: Dangerous freights, Hazmat transports, multimodal transports, security.

\section{INTRODUCTION}

Transporting chemical substances to serve the industries using and manufacturing chemicals (such as petrochemical plants and pharmaceutical companies, as well as paint, varnish, soap, and detergent manufacturers) is needed for the storage, production, processing, and distribution of raw materials, base chemicals, intermediates, etc. within and across regional, national, and international borders. Daily transportation activities of the so-called hazardous materials (hazmat) via roads, railways, inland waterways, and pipeline networks, are essential to national economies, and such transports are even essential to - and a necessary condition for - a healthy world economy and our modern day lives. In fact, service industries, including financial, medical, and social services, are only made possible by the wealthproducing activities of production industries and the transportation activities between the numerous chemical plants, storage- and production centers, etc. The competitiveness of all these sectors is partly dependent on the efficient supply of chemical products. It is for that reason that the chemical industry, including hazmat transportation, has been described as the 'anchor' of a modern economy [1-3]. Approximately 6\% of total cargo represents dangerous goods transportation. Hazmat transports are thus essential for the world economy and their importance is continuously rising [4].

\subsection{Safety versus security risks}

In the current global context of industrial activities, the prosperity and wealth of nations may indeed be heavily affected, to some extent, if a major disruption of the hazmat transportation system would occur. Millions of hazmat shipments move daily through worldwide transportation systems. Operational risks associated with these shipments can be generated by either accidental circumstances (safety risks) or by intentional actions (security risks) [5]. Thus, 
safety and security are two related concepts [6-8]; however, they have a different basis: safety is non-intentional, whereas security is intentional [9]. In the case of security, this implies that an aggressor who is influenced by the physical environment and by personal factors is present [10,11]. The hazmat transportation system obviously goes hand in hand with all kinds of safety and security risks.

Safety and security risks are to be identified, analyzed, assessed, and evaluated in a different way. An assessment of safety risks requires consideration of (safety-related) scenarios, consequences, exposure to the risks, (quantitative) frequencies or probabilities, or (qualitative) likelihood. In case of an assessment of security risks, (security-related) scenarios, (qualitative) likelihood, consequences, threat, vulnerability, and target attractiveness are to be taken into account. It should be noted that target attractiveness is in function of time, political climate, etc., and can thus rapidly change.

For safety risks, (safety) risk assessment methods are used, whereas threat analyses or vulnerability assessments form part of security risk assessment methods. Fixed risks are also quite different from moving (transport-related) risks, and taking security measures in case of hazmat transports often depends on the situation at hand. For example, with the exception of transport through pipeline, transported hazmat are not permanently present at a certain spatial point to perform transportation risk calculations. Spatial planning around a transportation route can differ greatly from the surroundings of a fixed installation within a chemical plant; taking risk-reducing measures is not always straightforward (e.g. an automatic sprinkler installation is very difficult to implement for hazmat transports, etc.), experts or specialists are not always present within a predefined period of time at a dangerous goods transport accident scene, etc.

\subsection{Safety and security risks with respect to hazmat transports}

Compared with the average non-hazmat truck shipments accident rate (which was 0.73 per million vehicle miles in the USA), hazmat truck shipment accidents remain rare events (on average 0.32 per million vehicle miles in the USA) [12]. Nonetheless, although the number of deaths and injuries due to all traffic accidents dwarfs the fatality and injury figures of hazmat-related accidents, public concern about the risk of hazmat incidents is rather intense. Even minor incidents involving chemical freights strongly attract the attention of the general public, policymakers, and industrialists. This is primarily due to the involuntary nature of the risk and the potential for significant consequences in case of such accidents. Despite the fact that there is genuine public concern about the operational risks associated with hazmat transportation systems, complete protection of these systems is economically and practically infeasible. Therefore, there is a need for a multi-disciplinary perspective on hazmat security, including taking the different transport modes into account. Safety and security management specialists need to collaborate with transport (and other) experts using methods, such as the mathematical techniques of multi-criteria analysis, game-theory, and/or operations research. Such a holistic managerial approach should lead to more objective and cost-effective assessments and prioritizations of defenses and countermeasures against the existing hazmat transportation threats.

Although until present, the number of security-related accidents involving hazardous substances is rather limited in the Western world, a wide variety of security threats do exist against hazmat transports. A chemical shipment can fall victim to a number of different types of attacks inspired by terrorism. These types of attacks, combined with recent accidents, are 
changing the perception and tolerance of managing the risks of hazmat transportation operations. The vulnerabilities of the transportation infrastructure and the potential consequences of hazmat transportation incidents urge policymakers to take action, resulting in worldwide calls for legislation directed at increased security, rerouting of hazmat shipments with emphasis on security, and the push for application of inherently safer technologies, leading to enhanced security as a natural by-product. Public and private stakeholders fully agree upon the need for dangerous freight transports to be made safe and secure and to be organized as efficiently as possible.

\subsection{The need for intelligent security countermeasures}

There are simply too many hazmat transports to protect all of them in an equally efficient way. Hence, 'Maginot Line' thinking should be abandoned and intelligent choices and decisions have to be made regarding the priority of which hazmat transport (which transport routes and which transport modes) need protection. The best defense against terrorist attacks on hazmat transport targets are effective hazmat transport security vulnerability assessments and collaboration between and across the private sector, local, national, and international cooperating authorities as well as the use of adequate mathematical techniques.

\section{IMPORTANCE OF SECURING HAZMAT TRANSPORTS}

As indicated in the previous section, global trade has resulted in more worldwide national and transborder shipments of raw materials, dangerous goods, hazardous wastes, etc., than ever before. The volume of traffic and the speed with which the transports move continue to increase in both developed and developing countries. Remarkably, there have been relatively few intentional mass-casualty disasters associated with hazmats transports, especially when one considers the volumes carried per container, the number of shipments each year, and the direct proximity of the public. Historically, only a very limited number of incidents causing mass casualties have happened worldwide, when expressed per billion ton-miles.

Until present, the terrorist threat to the hazmat transportation system has gained far less attention from political and industrial policymakers than the threat to passenger transport since very few terrorist organizations have made a serious attempt to either target hazmat transports or to use hazmat transports as their means of attack in countries belonging to the Western world. However, the repercussions of a terrorist attack on the hazmat transportation system may be substantial.

Terrorist actions may be targeted to obtain as many human fatalities as possible or to cause as much economic devastation as possible. At their worst, terrorist actions may be aimed at realizing both human fatalities and economic devastation. It is important to note that under the present circumstances, the hazmat transportation system, in the United States as well as in Europe or any other part of the world, if under attack in an intelligent way, can be employed by terrorists to attain both these goals simultaneously.

Especially in the transportation system, escalation effects from an attack may be farreaching. As an example, 191 people were killed and some 1,800 were injured and the European markets (FTSE) dropped by a calculated $\$ 55$ billion in the Madrid terrorist attack on March 11, 2004. As another example, the estimated cost on the entire supply chain of a weapon of mass destruction shipped via container is some \$1 trillion [13].

Therefore, to proactively limit the potential number of human fatalities and the huge economic costs, it is crucial that academic research is carried out from a multi-disciplinary 
and multi-modal viewpoint to identify, assess, and prioritize transborder transportation system security risks and to take proactive actions and countermeasures accordingly.

\section{UNI-MODAL VERSUS MULTI-MODAL TRANSPORTATION}

Dullaert et al. [14] indicate that since the beginning of multi-modal transportation, the academic literature has offered a variety of definitions. Faust [15] defines multi-modal transport as 'the transport of goods by at least two different modes of transport on the basis of a single multi-modal transport contract'. Hayuth [16] explains inter-modality as 'the movement of cargo from shipper to consignee by at least two different modes of transport under a single rate, through-billing, and through-liability. The objective of inter-modal transportation is to transfer goods in a continuous flow through the entire transport chain, from origin to final destination, in the most cost- and time-effective way'. At present, the European Union, the European Conference of Ministers of Transport (ECMT) and the United Nations Economic Commission for Europe (UN/ECE) have accepted the following definition of combined transport in Europe: 'Inter-modal transport where the major part of the journey, in Europe, is by rail, inland waterways or sea, and any initial and/or final legs carried out by road are as short as possible' [17].

Both in academic and professional publications, inter-modal, multi-modal, and combined transport are often used as synonyms. They all share the same difference with uni-modal transport: more than one transport mode is used for moving cargo from an origin to a destination, usually involving stopovers at terminals for changing transport modes.

When comparing different transport alternatives to determine an optimal transport route composed of different transport modes, one should not only consider, for example, the transportation costs of each alternative but also the security issues associated with each option.

Multi-modal transportation is very much prevalent in the chemical industry, using roads, railways, barges, ships, and pipelines to transport goods. A variety of companies are usually active within one of the available transportation and they rarely operate within several of the mode at the same time. Nonetheless, by transporting chemical products employing different modes (e.g. moving goods from road onto rail, ship or pipeline or vice versa, for security considerations), the chemical industry and its Logistics Service Providers can probably greatly improve their security scores.

Hence, the security resource allocation problem exists on both intra- and inter-modal levels. On an intra-modal dimension, the authorities or the companies responsible for the transport have to decide what security measures have to be taken on which transportation routes (belonging to the same mode) available between point A (e.g. a company, a city, or a storage park) and point $\mathrm{B}$. This decision regarding security resource allocations should take into account all existing and feasible uni-modal transportation routes between point $\mathrm{A}$ and point $\mathrm{B}$ and it should be repeated for all dangerous freights that the authorities or the companies wish to investigate. On an inter-modal dimension, the different available mode for transporting certain dangerous freights between point A and point B should be investigated and security resources allocated between the different modes. This adds an extra complexity to the uni-modal security resource allocation problem. Actually, multi-modal planning is more difficult than uni-modal planning, both on an operational (e.g. planning of individual shipments) and a tactical/strategic level (e.g. planning of flow of goods through the network). Therefore, an even stronger need for support by a transportation security risk model is present in the multi-modal case. Elaborating a user-friendly model and accompanying tool that 
supports decision-making by private and public stakeholders to allocate security resources from an intra-modal and an inter-modal viewpoint is thus very much needed.

In fact, the idea of developing a model or a tool addressing security-related issues and specifically aiming them at supporting decisions for preventing or mitigating intentional designed malicious acts on transportation infrastructure from a multi-modal perspective has only very recently gained attention in the academic world.

\section{HAZMAT TRANSPORT INDUSTRIAL SECURITY PRACTICES: AN INTERNATIONAL QUALITATIVE STUDY}

In this section, we qualitatively investigate current industrial security practices in Belgium and in Italy regarding hazmat transportation. The research objectives of our study were to obtain an insight into the current situation with regard to the knowledge, management and attitudes toward operational security of firms transporting dangerous goods and to learn whether security is a driver for multi-modal transportation.

An in-depth literature study has led to drafting four hypotheses, which are discussed hereafter. The hypotheses were studied via a survey of Belgian and Italian companies. The methodology that was used to gather the empirical data was telephone interviews using an interview guide containing a list of 19 questions. In total, 52 Belgian companies were contacted, from which 11 participated in the study; 67 Italian firms were contacted, from which 19 participated in the study. This reflects to a response rate of $25 \%$ for the whole study.

The first hypothesis was formulated as

'Security is a well-known concept within hazmat transportation firms. Companies are familiar with security techniques and measures to assess security risks'.

The study indicated that security is well known within hazmat transport companies. In the sample, transports are organized based solely on costs $(53 \%)$, based on costs and security $(40 \%)$, or based solely on security (3\%). Furthermore, a variety of methods exist to assess security risks. No single method is preferred (or better known) over another one. Some used techniques are: hazop, what-if analysis, safety-audits, checklists, and evacuation plans.

A differentiation of security measures is employed: human factor measures (43\%), organizational measures $(38 \%)$, and technical measures $(19 \%)$. The first hypothesis therefore can be accepted.

The second hypothesis was formulated as

'Vulnerability and threat analyses are essential approaches in dealing with hazmat transportation security'.

Vulnerability and threat analyses are very seldom used: only in $10 \%$ of the cases did participating companies carry out a Security Vulnerability Assessment. Those seldom cases were only represented by some major companies with more than $95 \%$ international transports, recognizing the potential threats for their transports. This hypothesis, thus, does not hold valid for the large majority of the participating firms.

The third hypothesis was formulated as

'Security is regarded as an important domain within hazmat transport firms, reflecting into plants' investment policies'.

Investments in security, in relation to the firms' revenues, are very low, both in Belgian and in Italian companies ( $<1 \%$ of revenues). Especially when comparing the security investments with potential costs in case of terrorist attacks, they seem to be highly insufficient. The third hypothesis can therefore also be rejected. 
The fourth hypothesis was formulated as

'Multi-modal hazmat transportation is well-known by transport firms and is used to increase security of hazmat transports'.

The study revealed that inter-modal transport is well known by transport firms, but it is seldom used to increase security: only one out of 30 companies participating in our research claimed to use multi-modal transport for security reasons. The main reason for using intermodal transportation is efficiency optimization (from a commercial viewpoint, a supply chain managerial viewpoint, etc.). Therefore, hypothesis four does only partially hold true.

As a conclusion and a recommendation from this international study, security deserves much more attention from industrial hazmat transporters. The next section describes some possible approaches that can be used by the academic world to enhance the importance of security from a theoretical viewpoint, and in this way to decrease the gap between industrial practice and academic knowledge.

\section{ADVANCING SECURITY ASSESSMENTS OF MULTI-MODAL HAZMAT TRANSPORTATION}

Verma and Verter [18] are the first to examine population exposure due to hazmat transportation through inter-modal service networks. In their 2010 paper [19], they suggest a lead-time-based approach for planning rail-truck inter-modal transportation of dangerous goods. Bell [20] shows that, for repeated hazmat shipments through a network, where the accident probabilities over the various links in the network are unknown, the safest strategy, in general, is to use multiple routes for each origin-destination pair. Bersani et al. [21] further demonstrate that spreading the risk both in space and in time further ameliorates the routing problem. Dadkar et al. [22] develop a game-theoretical model to represent the interaction of shipper/carrier and terrorist for hazmat transports and - by solving the model - give an idea of how routing decisions might be analyzed under terrorist threat. Garrido [23] presents mathematical models to identify possible hijacked vehicles' routes to vulnerable targets, assuming that probabilities of interception by law enforcement agents depend on the investment in defense resources. Murray-Tuite [24] demonstrates how Bayesian analysis can be used to update attack scenario probabilities after receiving new information on transportation risks.

However, to the best of the author's knowledge, no user-friendly multi-modal approach currently exists for assessing and prioritizing security risks (threats/vulnerabilities) related to the transportation of hazmat. The method should be understandable not only for academics but also for trained professionals and political decision makers. In addition, the method should allow for simulation exercises (e.g. the user should be able to translate countermeasure improvements into the results of the threat assessment).

Different possibilities exist to meet this need to develop a method for multi-modal assessment of hazmat transports. In any case, the approach implies the relative determination of hazmat transports or security countermeasures: different types of hazmat transports and/ or various preventative and/or mitigation measures are relatively ranked toward each other. This way, one can obtain a notion of the relative (security related) vulnerability of transport routes and transport modes, thereby taking, for example, infrastructure characteristics and types and amounts of various transported chemicals into account. Using the obtained ranking results, a decision-maker can make more objective decisions on taking countermeasures for a certain hazmat transport routes or can make a more neutral multi-modal choice of a hazmat transport route. 
A first possibility concerns the use of multi-criteria analysis for developing and implementing a tool to deal with security of multi-modal hazmat transports.

The methodology should present a user-friendly approach to determine relative security risk levels of the different modes of hazardous freight transport (e.g. road, railway, inland waterways, and pipeline transportation), taking into account various possible countermeasures. Likelihood parameters of security-related accidents in which dangerous freight is involved, with the possibility of causing fatalities in the surrounding population, should be considered, together with the consequences of accident scenarios, to determine transportation route security risk levels. Such an approach should lead to a multi-modal user-friendly security threat assessment tool, which can be used by policymakers as well as by industrialists (shippers or logistics service providers). The generic method would allow for comparing the security risk levels of the different routes of transportation of hazardous goods and for taking countermeasures from a uni-modal as well as from a multi-modal perspective.

A second possibility involves the development and the use of a game-theoretical model and tool.

Since the terrorist attacks on September 11, 2001, game theory has been increasingly employed as a mathematical tool to deal with security decisions faced with adaptive adversaries. In particular, recent literature includes Bier [25]; Bier et al. [26]; Zhuang and Bier [27]; Heal and Kunreuther [28]; Paruchuri et al. [29]; Bier et al. [30]; Dighe et al. [31]; Guikema and Aven [32]; and Zhuang et al. [33] See Sandler and Siqueira [34,] for an extensive survey. More specifically, gaining insight into the nature of optimal defensive investments yielding the best trade-off between investment costs and critical infrastructure security was also already subject of an important amount of scientific research. See Brown et al. [35]; Azaiez and Bier [36]; Levitin [37]; Patterson and Apostolakis [38]; Levitin and Hausken [39]; Hausken [40]; Liu et al. [41]; Hausken and Levitin [42]; Golany et al. [43]; and Reniers [44].

However, to date, no concrete attention has been paid to the multi-modal transportation security resources allocation decision problem from a game-theoretical viewpoint. This is thus a research subject deserving much more attention from the academia. In case of the multi-modal transportation problem, the focus should be on the development of an attackerdefender model (based on game theory). A dynamic game with incomplete information, in which the defender chooses how to allocate the security resources (on which transport routes, on which modes, etc.) and then an attacker chooses which target to attack (which route, which mode, etc.) according to a multi-attribute utility function, can be considered. A model focusing on multi-modal transportations of hazardous substances should make the decision process of taking security countermeasures allocations in a complex transportation network more objective and (subsequently) more justified.

Cox [45] indicates that the game theory and risk analysis are mutually reinforcing to obtain effective risk management recommendations for allocating security resources. Therefore, a tool based on multi-criteria analysis and one based on game-theory used by private and public stakeholders might lead to a truly more secured hazmat transportation system.

A third possibility consists of using meta-heuristics. Heuristic methods do not come with a guarantee that the optimal solution will be found. Instead, they attempt to find a solution that is 'as good as possible, in a computing time that is as small as possible'. Heuristics are more flexible than exact methods, in that the amount of time allowed to the method may be determined by the application: some applications require almost-instant decisions (e.g. rerouting a car when it has taken a wrong turn), whereas others may be allowed hours or even days (e.g. strategic decisions, such as determining the location of inter-modal terminals). A 
meta-heuristic is defined as a 'high-level problem-independent algorithmic framework that provides a set of guidelines or strategies to develop heuristic optimization algorithms' (Sörensen and Glover, to appear). It is not difficult to see that the multi-modal hazmat transportation optimization problems generally classify as both large and complex. For this reason, meta-heuristics present a possible approach to tackle such problems.

In today's global economy, many different decisions need to be taken regarding hazmat transports, both short-term operational decisions and long-term strategic and tactical decisions. Moreover, the amount of time that is available to solve problems of hazmat transportation is restricted. Although this is especially true for operational models in which short-term decisions are made, there is also a preference for strategic decisions to be as fast as possible. The reason for the latter is that such decisions are typically not taken in a oneshot way but by using an integrated decision tool in which the user can manually test certain assumptions. For a given user-input scenario, the optimization algorithm integrated into the decision support tool should be able to quickly determine a 'good enough' answer.

Hence, the sheer size and complexity of most realistic multi-modal hazmat transportation optimization problems, as well as the diversity of problems encountered in real life, plea for the use of meta-heuristic optimization tools.

\section{CONCLUSIONS}

Controlling and managing risks with regard to multi-modal hazmat transports become ever more important for industrialists and policymakers. Security risks especially (associated with intentional acts, such as terrorist attacks) are subject of the emerging research field devoted to the hazmat transportation system.

Following the results of an international survey, industrial practice with regard to the security of hazmat transports is characterized by the following: (i) there are no widely accepted and used analysis methods for security risks; (ii) vulnerability and threat assessment methods are seldom used, only by some major companies who are internationally active; (iii) security investments are very low compared with companies' revenues and with the firms' costs if a terrorist attack would be executed on these firms; and (iv) security is not an issue for a shift toward more multi-modal transportation.

Methodologies and accompanying software, therefore, need to be developed to deal with the complex multi-modal and multi-stakeholder hazmat transportation security problem and the associated security resources allocation problem. Three possible mutually reinforcing ways for advancing multi-modal hazmat security are represented by multi-criteria analysis, game-theory, and meta-heuristics. These mathematical techniques promise to help tackle hazmat transport security of the next generation.

\section{REFERENCES}

[1] Howitt, S. Keynote Report: the chemical industry, chartered institute of marketing, 2000.

[2] McKinnon, A. Supply chain excellence in the European chemical industry, the European petrochemical association (EPCA), Brussels, Belgium, 2004.

[3] Schreckenbach, T., Becker, W. Chemicals - Driving innovation in other industries. Value Creation. Strategies for the Chemical Industry, eds Budde, Felcht \& Frankemölle, 2nd Ed., Wiley, Weinheim, Germany, 2006.

[4] Reniers, G., Security of multimodal dangerous freight transport: the way forward, Safety and Security Engineering IV, eds Guarascio, Reniers, Brebbia, Garzia, WITPress, Southampton, UK, 2011. 
[5] CCPS, Center for Chemical Process Safety. Guidelines for Analyzing and managing the security vulnerabilities of fixed chemical sites, American Institute of Chemical Engineers: New York, USA, 2003.

[6] Aven, T. A unified framework for risk and vulnerability analysis covering both safety and security. Reliability Engineering and System Safety 6(92), pp. 745-754, 2007. doi: http://dx.doi.org/10.1016/j.ress.2006.03.008

[7] Johnston, R.G. Adversarial safety analysis: borrowing the methods of security vulnerability assessments. Journal of Safety Research 3(35), pp. 245-248, 2004. doi: http:// dx.doi.org/10.1016/j.jsr.2004.03.013

[8] Holtrop, D., Kretz, D., Onderzoek security \& safety: een inventarisatie van beleid, weten regelgeving. Nederland: Arcadis, 2008.

[9] Hessami, A.G. A system Framework for Safety and Security: the holistic paradigm. System Engineering (7), 2004. DOI: 10.1002/sys.10060. doi: http://dx.doi.org/10.1002/ sys. 10060

[10] Randall, L.A. 21st Century Security and CPTED, CRC Press, Boca Raton, USA, 2008.

[11] George, R. Critical infrastructure protection. International Journal for Critical Infrastructure Protection (1), pp. 4-5, 2008.

[12] Federal Motor Carrier Safety Administration. Comparative risks of hazardous materials and non-hazardous materials truck shipment accidents/incidents, Battelle, Ohio, USA, 2001.

[13] Zamparini, L. Transport Security in EU and US: Competing or complementary visions? Nectar workshop on transport security, Lecce, Italy, 5-6 Feb 2010.

[14] Dullaert, W., Vernimmen, B., Zamparini, L. Multimodal transport: historical evolution and logistics framework. Security Aspects of Uni- and Multi-modal Hazmat Transportation Systems, Wiley, Weinheim, Germany, 2011.

[15] Faust, P. Multimodal transport, in: Institute of Shipping Economics and Logistics, Port Management Textbook - Containerization: Bremen, pp. 219-231, 1985.

[16] Hayuth, Y. Intermodality: concept and practice, London, Lloyds of London Press Ltd., 149 p, 1987.

[17] UIRR. International Union of Road Rail transport Companies. http://www.uirr.com/en/ road-rail-ct.html, 2011.

[18] Verma, M., Verter, V. Railroad transportation of dangerous goods: population exposure to airborne toxins. Computers and Operations Research, 34, pp. 1287-1303, 2007. doi: http://dx.doi.org/10.1016/j.cor.2005.06.013

[19] Verma, M., Verter, V. A lead-time based approach for planning rail-truck intermodal transportation of dangerous goods. European Journal of Operational Research, 202, pp. 696-706, 2010. doi: http://dx.doi.org/10.1016/j.ejor.2009.06.005

[20] Bell, M.G.H. Mixed route strategies for the risk-averse shipment of hazardous materials. Networks and Spatial Economics, 6, 253-265, 2006. doi: http://dx.doi.org/10.1007/ s11067-006-9283-X

[21] Bersani, Ch., Minciardi, R., Tomasoni, A.M., Sacile, R. Risk Averse Routing of Hazardous Materials with Scheduled Delays. In Security and Environmental Sustainability of Multimodal Transport, Bell, M.G.H., Hosseinloo, S.H., Kanturska, U. (Edits.), NATO Science for Peace and Security Series-C: Environmental Security, Springer, Dordrecht, The Netherlands, 2009.

[22] Dadkar, Y., Nozick, L., Jones, D. Routing of Hazardous Material Shipments Under the Threat of Terrorist Attack, In Security and Environmental Sustainability of Multimodal 
Transport, Bell, M.G.H., Hosseinloo, S.H., Kanturska, U. (Edits.), NATO Science for Peace and Security Series-C: Environmental Security, Springer, Dordrecht, The Netherlands, 2009.

[23] Garrido, R.A., 2009. Terrorists and Hazmat: A Methodology to Identify Potential Routes, In Security and Environmental Sustainability of Multimodal Transport, Bell, M.G.H., Hosseinloo, S.H., Kanturska, U. (Edits.), NATO Science for Peace and Security Series-C: Environmental Security, Springer, Dordrecht, The Netherlands.

[24] Murray-Tuite, P. Bayesian analysis for transportation risk, In Security and Environmental Sustainability of Multimodal Transport, Bell, M.G.H., Hosseinloo, S.H., Kanturska, U. (Edits.), NATO Science for Peace and Security Series-C: Environmental Security, Springer, Dordrecht, The Netherlands, 2009.

[25] Bier, V.M. Choosing what to protect. Risk Analysis, 27(3), pp. 607-620, 2007. doi: http://dx.doi.org/10.1111/j.1539-6924.2007.00906.x

[26] Bier, V.M., Oliveros S. \& Samuelson L. Choosing what to protect: strategic defensive allocation against an unknown attacker. Journal of Public Economic Theory, 9, pp. 563-587, 2007. doi: http://dx.doi.org/10.1111/j.1467-9779.2007.00320.x

[27] Zhuang, J. \& Bier, V.M. Balancing Terrorism and Natural Disasters - Defensive Strategy with Endogenous Attack Effort. Operations Research, 55(5), pp. 976-991, 2007. doi: http://dx.doi.org/10.1287/opre.1070.0434

[28] Heal, G., Kunreuther, H. Modeling interdependent risks. Risk Analysis, 27(3), pp. 621-634, 2007. doi: http://dx.doi.org/10.1111/j.1539-6924.2007.00904.X

[29] Paruchuri, P., Pearce, J.P., Marecki, J., Tambe, M., Ordonez, F. \& Kraus, S. Efficient algorithms to solve Bayesian Stackelberg games for security applications. AAA'08: proceedings of the 23rd national conference on artificial intelligence, vol. 3, AAAI Press, pp. 1559-1562, 2008.

[30] Bier, V.M., Haphuriwat, N., Menoyo, J., Zimmerman, R. \& Culpen, A. 2008. Optimal resource allocation for defense of targets based on differing measures of attractiveness. Risk Analysis, 28(3), pp. 763-770. doi: http://dx.doi.org/10.1111/j.15396924.2008.01053.x

[31] Dighe, N., Zhuang J., \& Bier V.M. Secrecy in defensive allocations as a strategy for achieving more cost-effective attacker deterrence, International Journal of Performability Engineering, special issue on System Survivability and Defense against External Impacts, 5(1), pp. 31-43, 2009.

[32] Guikema, S.D. \& Aven, T. Assessing risk from intelligent attacks: a perspective on approaches. Reliability Engineering and System Safety, 95, pp. 478-483, 2010. doi: http://dx.doi.org/10.1016/j.ress.2009.12.001

[33] Zhuang, J., Bier, V.M., \& Alagoz, O., Modeling Secrecy and Deception in a Multipleperiod Attacker-Defender Signaling Game, European Journal of Operational Research, 203(2), pp. 409-418, 2010. doi: http://dx.doi.org/10.1016/j.ejor.2009.07.028

[34] Sandler, T. \& Siqueira, K. Games and Terrorism. Simulation \& Gaming, 40(2), pp. 164-192, 2009. doi: http://dx.doi.org/10.1177/1046878108314772

[35] Brown, G., Carlyle, M., Salmeron, J. \& Wood, K. Defending Critical Infrastructure. Interfaces, 36, pp. 530-544, 2006. doi: http://dx.doi.org/10.1287/inte.1060.0252

[36] Azaiez, N. \& Bier, V.M. Optimal Resource Allocation for Security in Reliability Systems. European Journal of Operational Research, 181(2), pp. 773-786, 2007. doi: http://dx.doi.org/10.1016/j.ejor.2006.03.057 
[37] Levitin, G. Optimal Defense Strategy Against Intentional Attacks. IEEE Transactions on Reliability 56(1), pp. 148-156, 2007. doi: http://dx.doi.org/10.1109/TR.2006.884599

[38] Patterson, S. \& Apostolakis, G., Identification of critical locations across multiple infrastructures for terrorist actions, Reliability Engineering \& System Safety, 92(9), pp. 1183-1203, 2007. doi: http://dx.doi.org/10.1016/j.ress.2006.08.004

[39] Levitin, G. \& Hausken, K. Protection vs. Redundancy in Homogeneous Parallel Systems. Reliability Engineering \& System Safety, 93(10), pp. 1444-1451, 2008. doi: http://dx.doi.org/10.1016/j.ress.2007.10.007

[40] Hausken, K., Strategic defense and attack for reliability systems. Reliability Engineering and System Safety, 93(11), pp. 1740-1750, 2008. doi: http://dx.doi.org/10.1016/j. ress.2007.11.002

[41] Liu, D., Wang, X. \& Camp, J. Game-theoretic modeling and analysis of insider threats. International Journal of Critical Infrastructure Protection, 1, pp. 75-80, 2008. doi: http://dx.doi.org/10.1016/j.ijcip.2008.08.001

[42] Hausken, K. \& Levitin, G. Minmax defense strategy for complex multi-state systems. Reliability Engineering and System Safety, 94(2), pp. 577-587, 2009. doi: http://dx.doi. org/10.1016/j.ress.2008.06.005

[43] Golany, B., Kaplan, E.H., Marmur, A. \& Rothblum, U.G. Nature plays with dice terrorists do not: allocating resources to counter strategic versus probabilistic risks. $E u$ ropean Journal of Operational Research, 192(1), pp. 198-208, 2009. doi: http://dx.doi. org/10.1016/j.ejor.2007.09.001

[44] Reniers, G., An external domino effects investment approach to improve cross-plant safety within chemical clusters. Journal of Hazardous Materials, 177(1-3), pp. 167174, 2010. doi: http://dx.doi.org/10.1016/j.jhazmat.2009.12.013

[45] Cox, L.A., Game Theory and Risk Analysis. Risk Analysis, 29(8), pp. 1062-1068, 2009. doi: http://dx.doi.org/10.1111/j.1539-6924.2009.01247.x 